OPEN ACCESS

Edited by:

Giuseppe Scarcella,

National Research Council (CNR), Italy

Reviewed by:

Chongliang Zhang,

Ocean University of China, China

Yuan Li,

Third Institute of Oceanography, State

Oceanic Administration, China

${ }^{*}$ Correspondence:

Kui Zhang

zhangkui@scsfri.ac.cn

Specialty section:

This article was submitted to Marine Fisheries, Aquaculture

and Living Resources,

a section of the journal

Frontiers in Marine Science

Received: 31 May 2021

Accepted: 12 July 2021

Published: 30 July 2021

Citation:

Zhang K, Li J, Hou G, Huang Z, Shi D, Chen Z and Qiu Y (2021) Length-Based Assessment of Fish

Stocks in a Data-Poor, Jointly Exploited (China and Vietnam) Fishing

Ground, Northern South China Sea.

Front. Mar. Sci. 8:718052.

doi: 10.3389/fmars.2021.718052

\section{Length-Based Assessment of Fish Stocks in a Data-Poor, Jointly Exploited (China and Vietnam) Fishing Ground, Northern South China Sea}

\author{
Kui Zhang ${ }^{1,2,3 *}$, Jiajun Li1,2, Gang Hou ${ }^{4}$, Zirong Huang ${ }^{1,2}$, Dengfu Shi', Zuozhi Chen ${ }^{1,2,3}$ \\ and Yongsong Qiu'1,2
}

${ }^{1}$ South China Sea Fisheries Research Institute, Chinese Academy of Fishery Sciences, Guangzhou, China, ${ }^{2}$ Key Laboratory of Open-Sea Fishery Development, Ministry of Agriculture and Rural Affairs, Guangzhou, China, ${ }^{3}$ Southern Marine Science and Engineering Guangdong Laboratory, Guangzhou, China, ${ }^{4}$ College of Fisheries, Guangdong Ocean University, Zhanjiang, China

The Beibu Gulf is one of the most important fishing grounds in the South China Sea (SCS), and the fisheries resources in this area are exploited by both China and Vietnam. In recent decades, some indications of overfishing have appeared, including declining catch rates, frequently changing catch composition, and shrinking body sizes in main commercial fish species. Due to limited data availability, only a small subset of exploited fish stocks in this area has been assessed. Here, we applied two length-based methods, electronic length frequency analysis (ELEFAN) and length-based Bayesian biomass estimation (LBB), to stock assessment of nine exploited fish species in the Beibu Gulf. There were total 53, 652 length records of 30 target stocks used in this study during the survey period from 1960 to 2015. The results showed that the two length-based methods presented different ability in estimating exploitation rate $(E)$, and the estimated $E$ ranged from 0.34 to 0.87 using ELEFAN method while ranged from 0.26 to 0.86 using LBB method. The prior information from ELEFAN method was effective for LBB method, as there were significant differences in $66.7 \%$ of the 30 target stocks in estimated $L_{\text {inf }}$, and $93.3 \%$ in estimated $B / B_{M S Y}$, using LBB method with and without prior information. The estimated $L_{C} / L_{C_{-} \text {opt }}$ and $B / B_{M S Y}$ of LBB method suggest a pressing situation for the fisheries in the Beibu Gulf, as $86.7 \%$ of the 30 target stocks had been suffering from growth overfishing $\left(L_{C} / L_{C_{-} o p t}<1\right)$, and $83.3 \%$ had been overexploited or fully exploited $\left(B / B_{M S Y} \leq 1.2\right)$. In addition, we suggest using both ELEFAN and LBB methods to fit length-frequency data of data-poor fish stocks because they are complementary in estimating management reference points. We also emphasize collaboration mechanism should be established by China and Vietnam for the sustainability and recovery of fishery resources in the Beibu Gulf.

Keywords: Beibu Gulf, electronic length frequency analysis, length-based Bayesian estimation, prior information, exploitation rate, management 


\section{INTRODUCTION}

Marine fisheries resources are an important source of animal protein and micronutrients, and provide employment opportunities and income for people worldwide [Food and Agriculture Organization (FAO) (2016); Pauly and Zeller, 2016]. As a result of widespread overfishing leading to sequential depletion of exploited stocks, global fishery catch has been stagnating, then gradually decreasing since the late 1980s (Kleisner et al., 2013). Stock assessment is a basic work to carry out modern management and maintain fishery sustainability. With the improvement of computer simulation ability and multi-disciplinary collaboration, stock assessment methods have been developed rapidly. The stock assessment models tend to be more diversified, and their structures become more complicated (Maunder and Punt, 2013). The classical assessment models always need a large amount of statistical and survey data, including catch, abundance index and even age structure. However, most of exploited fisheries, especially in developing countries, do not have the data required for traditional methods and are considered data-poor. Consequently, only $20 \%$ of global catch comes from assessed species, and less than $1 \%$ of species have been assessed (Costello et al., 2012). The severity of this problem has been gradually realized, and increasing alternative methods for data-poor fisheries have been building in recent years (Dick and Maccall, 2011; Martell and Froese, 2013; Cadrin and Dickey-Collas, 2015; Hordyk et al., 2015; Froese et al., 2018).

At present, two types of methods are commonly used in data-poor fisheries, the catch-based methods and the lengthbased methods (Liang et al., 2020). The catch-based methods estimate sustainable yield or maximum sustainable yield (MSY) of the target population using catch time series and auxiliary data, e.g., intrinsic rate of increase, natural mortality, and age at maturity. The length-based methods can use lengthfrequency data to estimate growth, mortality and development status, e.g., exploitation rate, and relative stock size $\left(B / B_{M S Y}\right)$. Electronic length frequency analysis (ELEFAN) is widely used to fit von Bertalanffy growth function and estimate growth and mortality parameters for data-poor fisheries (Pauly and David, 1981). It enables users to formulate some management options for fisheries, especially in data-poor, tropical areas. Recently, a new length-based method, length-based Bayesian biomass estimation (LBB), was developed to estimate $B / B_{M S Y}$, and the current exploited biomass relative to the unexploited biomass $\left(B / B_{0}\right)$ for data-poor fish stocks (Froese et al., 2018). Compared to statistical catch data, length-frequency data is more convenient to collect due to the lower time and economic cost. Size-related measures (e.g., mean length, length at first sexual maturity) have long been used as indicators of response to population decline, especially in tropical waters where fish age are difficult to be identified, and data poor areas where historical catch data are not counted accurately. The lengthbased methods avoids relying on this incomplete dataset and instead used size composition data gathered from a range of sources to generate species-level assessments (Nadon et al., 2015), which obviously improves fisheries management in developing countries (Baldé et al., 2019). In addition, the assessment efficiency of catch-based methods largely depends on the accuracy of statistical catch data. However, marine fisheries catch data were distorted due to neglected small-scale fisheries, illegal fisheries, and discarded bycatch (Watson and Pauly, 2001; Pauly and Zeller, 2016). The systematic distortions in catch trends will impact the assessment results and prevent effective management.

The South China Sea (SCS) is located at the center of the Indo-West Pacific region, and is a representative sea of data-poor fisheries (Zhang et al., 2017). Despite its vast sea area, most of the fishing efforts and landings from the People's Republic of China (here after referred to as 'China') are concentrated in the northern continental shelf (Qiu et al., 2008). The northern SCS are important spawning and feeding grounds for commercial fish stocks, as well as marine fishing grounds. Since China's reform and opening up, the demand for seafood has increased with fast growth in the economy of coastal areas. Rapid growth in the number of marine fishing vessels and catches from the 1970s to 1990s had resulted in the decline of offshore fishery resources in the northern SCS (Zhang et al., 2017), especially in typical semiclosed bays (Zhang et al., 2020a,b). The Beibu Gulf covers an area of $12.8 \times 10^{3} \mathrm{~km}^{2}$, and is surrounded by the land territories of China and Socialist Republic of Vietnam (here after referred to as 'Vietnam') (Figure 1). It is highly productive and rich in fishery resources, and has been one of China's four major fishing grounds (Qiu et al., 2008). The Chinese and Vietnamese governments signed a Fishery Cooperative Agreement in 2000 (Qiu et al., 2008), and designed a joint fishing zone (Figure 1) in the Beibu Gulf (allow fishing for both countries). In recent six decades, fish community structure in Beibu Gulf has changed observably, from demersal to pelagic species and from high-trophic-level to low-trophic-level species (Su et al., 2021). The major commercial fish stocks, e.g., threadfin porgy Evynnis cardinalis, tend to be smaller body size, and earlier sexual maturity (Zhang et al., 2020a). It is commonly agreed that for risk avoidance and economic benefits, biomass $(B)$ of fish stocks must be above the MSY level $\left(B_{M S Y}\right)$ and fishing pressure $(F)$ must be below the MSY level $\left(F_{M S Y}\right)$ based on the MSY framework (Froese et al., 2020). However, limited research on fish stock assessment based on the MSY framework has been undertaken (Zhang et al., 2017), so it is necessary to establish alternative methods in the Beibu Gulf.

In this paper, we applied the two above-mentioned lengthbased methods (ELEFAN and LBB) to stock assessment for nine exploited fish stocks in the Beibu Gulf. ELEFAN is widely used in fish stock assessment in Chinese waters, and many of the main commercial species have been assessed by this method, e.g., largehead hairtail Trichiurus japonicus (Zhou et al., 2002), small yellow croaker Larimichthys polyactis (Liu et al., 2012). LBB is a newly developed method and has been recently introduced to stock assessment in Chinese waters (Liang et al., 2020; Zhang et al., 2021b). The assumptions and computational procedures of the two methods are quite different (Pauly and David, 1981; Froese et al., 2018). Until now, how prior information affect the performance of LBB method and comparison of assessment results with ELEFAN method in data-poor fisheries have not been 


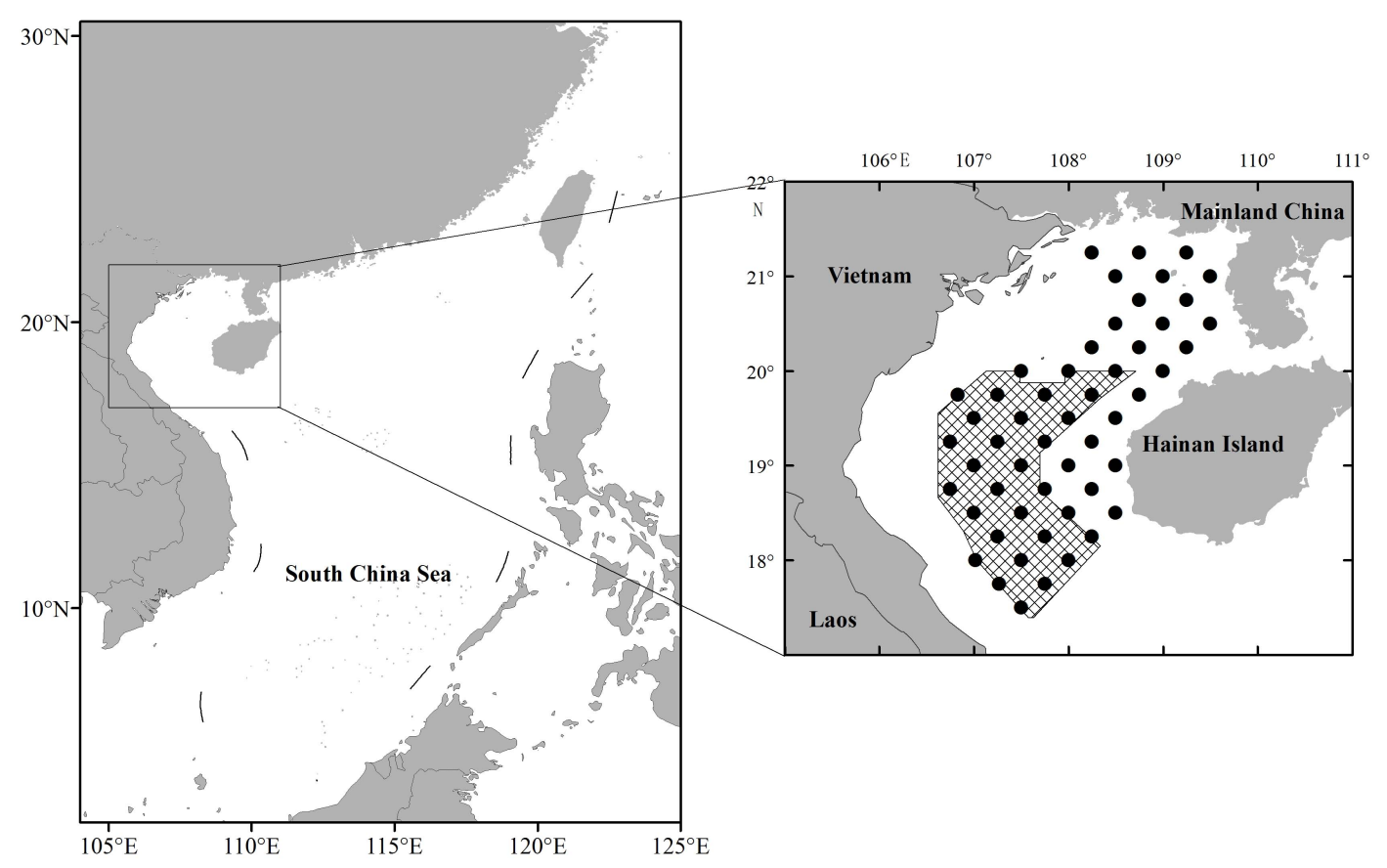

FIGURE 1 | Map of Beibu Gulf, including the joint fishing zone (grids) between China and Vietnam, and sampling stations (dots).

documented. The objectives of this study were to: (1) provide an overview of exploitation status of exploited fish stocks in the Beibu Gulf; (2) compare the assessment results of the two lengthbased methods; and (3) compare the performance of LBB method with and without prior information. The results may contribute to providing a scientific basis to assist sustainable utilization and management of fish stocks in data-poor areas.

\section{MATERIALS AND METHODS}

\section{Data Collection}

Length data analyzed in this study were from bottom-trawl surveys (1960-2015) conducted by the SCS Fisheries Research Institute. The sampling stations (Figure 1) were predetermined before the surveys and consistent from year to year. Each station was investigated once and trawled for $1 \mathrm{~h}$, with an average hauling speed of 3-4 knots in all surveys. The mesh size of the bottom-trawl nets ranged from 120 to $200 \mathrm{~mm}$, with $30-40 \mathrm{~mm}$ cod-end mesh size in all the surveys. Surveys were conducted monthly in the 1960s and quarterly in other periods (Table 1). All captured fishery samples were identified to the species level, and biological data including length, weight, sexual maturity and stomach fullness for main commercial species were measured. The individuals were randomly sampled for measurement and laboratory bioassays. For each species, if fewer than 50 individuals were caught in a station, all were cryopreserved for laboratory bioassays; otherwise, 50 individuals were sampled randomly and measured. For each fish, the standard length was measured to the nearest millimeter.
Nine exploited fish stocks, including Japanese scad (Decapterus maruadsi), threadfin porgy (Evynnis cardinalis), yellowbelly threadfin bream (Nemipterus bathybius), golden threadfin bream (Nemipterus virgatus), red bigeye (Priacanthus macracanthus), purple-spotted bigeye (Priacanthus tayenus), brushtooth lizardfish (Saurida undosquamis), Japanese jack mackerel (Trachurus japonicus), and largehead hairtail (Trichiurus japonicus), were selected in this study regarding their high economic values and large catches in the northern SCS (Qiu et al., 2008; Zhang et al., 2017; Su et al., 2021). There were total 53, 652 length records of the nine fish species during different sampling years used in this study (total 30 assessment sequences in Table 1). Anal length was used for T. japonicas, fork length for D. maruadsi and T. japonicas, and body length for the other six fish species.

\section{ELEFAN Method}

The growth of the fish stocks was modeled by the von Bertalanffy equation (von Bertalanffy, 1938):

$$
L_{t}=L_{\text {inf }}\left(1-\exp \left(-K\left(t-t_{0}\right)\right)\right)
$$

where $L_{t}$ is length $(\mathrm{cm})$ at age $t, L_{\text {inf }}$ the asymptotic length, $K$ is the von Bertalanffy growth coefficient, and $t_{0}$ is the theoretical age at length zero. The ELEFAN I routines incorporated in the FiSAT II (Gayanilo and Pauly, 1997) software were used to fit growth curves to the restructured length-frequency data. Using both the "automatic search routine" and the "response surface analysis" within ELEFAN, it was possible to achieve the best fit for the growth curve (best-fitting combination of $L_{\text {inf }}$ and $K$ ) to the length-frequency data. 
TABLE 1 | Summary of samplings and length data for nine fish stocks collected during 1962-2012 for stock assessment in Beibu Gulf, South China Sea.

\begin{tabular}{|c|c|c|c|c|c|}
\hline Species & Sequence & Sampling year & $\begin{array}{l}\text { Standard length } \\
\text { range }(\mathrm{mm})\end{array}$ & $\begin{array}{c}\text { Numbers of } \\
\text { individuals measured }\end{array}$ & $\begin{array}{l}\text { Sampling } \\
\text { intervals }\end{array}$ \\
\hline \multirow[t]{7}{*}{ Decapterus maruadsi } & 1 & 1992 & $90-270$ & 635 & Quarterly \\
\hline & 2 & 1998 & $32-300$ & 1714 & Quarterly \\
\hline & 3 & 2006 & $76-264$ & 1049 & Quarterly \\
\hline & 4 & 2007 & $67-250$ & 1028 & Quarterly \\
\hline & 5 & 2009 & $86-235$ & 1226 & Quarterly \\
\hline & 6 & 2010 & $96-215$ & 465 & Quarterly \\
\hline & 7 & 2012 & $75-256$ & 1318 & Quarterly \\
\hline \multirow[t]{4}{*}{ Evynnis cardinalis } & 8 & 1962 & $40-240$ & 5201 & Monthly \\
\hline & 9 & 1999 & $57-230$ & 1120 & Quarterly \\
\hline & 10 & 2006 & $41-196$ & 2055 & Quarterly \\
\hline & 11 & 2015 & 23-202 & 2783 & Quarterly \\
\hline \multirow[t]{3}{*}{ Nemipterus bathybius } & 12 & 1992 & $51-220$ & 650 & Quarterly \\
\hline & 13 & 1997 & $51-200$ & 870 & Quarterly \\
\hline & 14 & 2009 & $41-230$ & 450 & Quarterly \\
\hline \multirow[t]{8}{*}{ Nemipterus virgatus } & 15 & 1960 & $36-282$ & 6781 & Monthly \\
\hline & 16 & 1962 & $46-275$ & 2356 & Monthly \\
\hline & 17 & 1992 & $68-300$ & 976 & Quarterly \\
\hline & 18 & 1998 & $43-300$ & 3168 & Quarterly \\
\hline & 19 & 2006 & $60-316$ & 1467 & Quarterly \\
\hline & 20 & 2007 & $75-308$ & 670 & Quarterly \\
\hline & 21 & 2009 & $63-310$ & 828 & Quarterly \\
\hline & 22 & 2012 & $75-272$ & 545 & Quarterly \\
\hline \multirow[t]{2}{*}{ Priacanthus macracanthus } & 23 & 1999 & $55-300$ & 1722 & Quarterly \\
\hline & 24 & 2015 & $57-303$ & 1295 & Quarterly \\
\hline Priacanthus tayenus & 25 & 1999 & $55-287$ & 421 & Quarterly \\
\hline Saurida undosquamis & 26 & 1999 & $11-435$ & 6467 & Quarterly \\
\hline Trachurus japonicus & 27 & 1999 & 90-290 & 1170 & Quarterly \\
\hline \multirow[t]{3}{*}{ Trichiurus japonicus } & 28 & 1982 & $132-605$ & 432 & Quarterly \\
\hline & 29 & 1999 & $20-670$ & 3662 & Quarterly \\
\hline & 30 & 2015 & $61-528$ & 1128 & Quarterly \\
\hline
\end{tabular}

The parameter $t_{0}$ were calculated using the empirical equation (Pauly, 1983):

$$
\log _{10}\left(-t_{0}\right)=-0.3922-0.275 \log _{10} L_{\mathrm{inf}}-1.038 \log _{10} K
$$

Total mortality $(Z)$ was estimated by the length-converted catch curve procedure (Pauly, 1983):

$$
\ln \left(N_{i} / \Delta t_{i}\right)=c-Z t_{i}^{\prime}
$$

where $N_{i}$ is the number of fish caught in a given length class $i$, $t_{i}{ }^{\prime}$ is the relative age corresponding to length class $i, \Delta t_{i}$ is the time needed for growing through the length class $i$, and $c$ is the intercept of the linear equation, respectively.

The instantaneous natural mortality $(M)$ was calculated (Pauly, 1983) by:

$$
\ln M=-0.0152-0.279 \ln L_{\mathrm{inf}}+0.654 \ln k+0.463 \ln T
$$

where $T$ is the mean environmental temperature. Fishing mortality $(F)$ was calculated by subtracting $M$ from $Z$, and the exploitation ratio $(E)$ was obtained from $F / Z$.

\section{LBB Method}

Growth in body length is also assumed to follow the von Bertalanffy growth function (von Bertalanffy, 1938) in the LBB method (Froese et al., 2018).

Most of commercially exploited fish species grow throughout their lifetime, and their body size would approach the asymptotic length $L_{\text {inf }}$ if mortality were zero, which can be expressed by:

$$
P_{L / L_{\mathrm{inf}}}=\left(1-\frac{L}{L_{\mathrm{inf}}}\right)^{M / K}
$$

where $P_{L / L i n f}$ is the probability to survive to length $L / L_{\text {inf }}$, which is solely a function of the $M / K$ ratio.

The LBB method assumes that the selectivity of fishing gear is trawl-like, i.e., small individuals (length $<L_{x}$ ) can not be caught, all individuals will be caught if exceed a certain body size (length $>L_{\text {start }}$ ), and part of the individuals are caught when length between $L_{x}$ and $L_{\text {start }}$. The gear selectivity can be expressed by the following equation:

$$
S_{L}=\frac{1}{1+\mathrm{e}^{-\alpha\left(L-L_{c}\right)}}
$$


where $S_{L}$ is the fraction of individuals that are retained by the gear at length $L, L_{c}$ is the length where $50 \%$ of the individuals are retained by the gear, and $\alpha$ represents the steepness of the ogive (Quinn and Deriso, 1999).

Combining the equations (1), (5), and (6), and rearranging lead to:

$$
\begin{gathered}
N_{L_{i}}=N_{L_{i-1}}\left(\frac{L_{\mathrm{inf}}-L_{i}}{L_{\mathrm{inf}}-L_{i-1}}\right)^{\frac{M}{K}+\frac{F}{K} S_{L_{i}}} \\
C_{L_{i}}=N_{L_{i}} S_{L_{i}}
\end{gathered}
$$

where $N_{L i}$ and $N_{L i-1}$ are the numbers of individuals in length class $L_{i}$ and the previous length class $L_{i-1}$, respectively. To minimize the required parameters, the ratios $M / K$ and $F / M$ are estimated, instead of the absolute values of $F, M$, and $K$ in the LBB analysis. In other words, the increase in fish body length can be used as a proxy for its life time, and by using ratios instead of absolute values the units of time and biomass cancel out (Froese et al., 2018).

The Bayesian Gibbs sampler JAGS within $\mathrm{R}$ statistical language (version 4.0.3) was used to fit the observed proportions at-length to their expected values:

$$
\hat{p}_{L_{i}}=\frac{\hat{N}_{L_{i}}}{\sum \hat{N}_{L_{i}}}
$$

where $p_{L i}$ is the observed proportions-at-length, $\hat{p}_{L_{i}}$ is the mean values for $p_{L i}, \hat{N}_{L_{i}}$ denotes the mean values for $N_{L i}$, which has been mentioned in equation (7).

The observed and predicted length distributions were then fitted by assuming Dirichlet-multinomial distribution (Thorson et al., 2017), which was proposed for fitting size and age composition in stock assessment models using a Bayesian framework. Proportions-at-length assume Dirichlet-multinomial distribution with an effective sample size of 1,000 , which was chosen based on desirable performance across various simulation-testing trial scenarios (Froese et al., 2018).

The following equations are used to approximate the population status through the estimated quantities $L_{i n f}, L_{c}$, $M / K$, and $F / K$. First, the length $L_{o p t}$ representing the maximum biomass of unexploited cohort is obtained from:

$$
L_{\mathrm{opt}}=L_{\mathrm{inf}}\left(\frac{3}{3+\frac{M}{K}}\right)
$$

With a given fishing pressure $F / M$, the length at first capture $L_{c_{-} \text {opt }}$ that maximizes catch and biomass can be obtained from:

$$
L_{\text {c_opt }}=\frac{L_{\text {inf }}\left(2+3 \frac{F}{M}\right)}{\left(1+\frac{F}{M}\right)\left(3+\frac{M}{K}\right)}
$$

An index catch per unit of effort $(C P U E / R)$ is obtained as dividing relative yield-per-recruit $\left(Y^{\prime} / R\right)$ by $F / M$, which can be described as:

$$
\begin{aligned}
& \frac{C P U E^{\prime}}{R}=\frac{\frac{Y^{\prime}}{R}}{\frac{F}{M}}=\frac{1}{1+F / M}\left(1-L_{\mathrm{c}} / L_{\text {inf }}\right)^{M / K} \\
& \left(1-\frac{3\left(1-L_{\mathrm{c}} / L_{\text {inf }}\right)}{1+1 /(M / K+F / K)}+\frac{3\left(1-L_{\mathcal{C}} / L_{\text {inf }}\right)^{2}}{1+2 /(M / K+F / K)}-\frac{\left(1-L_{\mathcal{C}} / L_{\text {inf }}\right)^{3}}{1+3 /(M / K+F / K)}\right)
\end{aligned}
$$

The relative biomass in the exploited phase of the fish population if no fishing takes place is given by:

$$
\begin{aligned}
& \frac{B_{0}^{\prime}>L_{c}}{R}=\left(1-L_{\mathrm{c}} / L_{\mathrm{inf}}\right)^{M / K} \\
& \left(1-\frac{3\left(1-L_{\mathrm{c}} / L_{\mathrm{inf}}\right)}{1+\frac{1}{M / K}}+\frac{3\left(1-L_{\mathrm{c}} / L_{\mathrm{inf}}\right)^{2}}{1+\frac{2}{M / K}}-\frac{\left(1-L_{\mathrm{c}} / L_{\mathrm{inf}}\right)^{3}}{1+\frac{3}{M / K}}\right)
\end{aligned}
$$

where $B_{0}{ }^{\prime}>L_{c}$ denotes the exploitable fraction $\left(>L_{c}\right.$ ) of the unfished biomass $\left(B_{0}\right)$.

The ratio of fished to unfished biomass is described as:

$$
\frac{B}{B_{0}}=\frac{\frac{C P U E^{\prime}}{R}}{\frac{B_{0}^{\prime}>L_{\mathrm{c}}}{R}}
$$

A proxy for the relative biomass that can produce $B_{M S Y} / B_{0}$ was obtained by re-running Equations (12-14) with $F / M=1$ and $L_{c}=L_{c_{-} \text {opt }}$ (Froese et al., 2018).

Hordyk et al. (2019) indicated that the LBB analysis did not correct for the pile-up effect (pile-up of abundance observations in length classes used as bins in length-frequency analyses), and may result in a biased estimate of $F$ and $M / K$. Therefore, we applied other two modified LBB model (Froese et al., 2019) on the length data of the 9 exploited fish species from Beibu Gulf. The two models, LBB-1 (full correction for the pile-up effect), and LBB-2 (let the Bayesian model determine the degree of correction based on the best fit to the available data) were based on the original LBB equation, and corrected for the pileup effect.

In this study, we also analyzed the performance of LBB method with and without prior information. The prior information of parameters $L_{\text {inf }}$ and $Z / K$ were from the output of ELEFAN method. All the analysis was implemented using LBB_33a.R, an R-code algorithm presented by Froese et al. $(2018,2019)$. Fish stocks were classified to three exploitation statuses based on the estimates of $B / B_{M S Y}$, overexploited status was assigned where $B / B_{M S Y}<0.8$, fully exploited status where $0.8 \leq B / B_{M S Y} \leq 1.2$, and underdeveloped status where $B / B_{M S Y}>1.2$ (Amorim et al., 2019). Besides, the stocks are considered as suffering from growth overfishing when the estimated $L_{c} / L_{c_{-} \text {opt }}<1$ (Liang et al., 2020; Zhang et al., 2021b).

\section{RESULTS}

\section{Comparison of Assessment Results Between ELEFAN and LBB Method}

The estimated asymptotic lengths for all assessment sequences ranged from 22.0 to $70.0 \mathrm{~cm}$ using ELEFAN method while ranged from 22.0 to $70.3 \mathrm{~cm}$ using LBB method. There were not significant differences in estimated $L_{\text {inf }}$ between ELEFAN method and LBB method, in all assessment sequences $(p>0.05)$, except D. maruadsi stock of 2006 $(t=5.37, p<0.05)$, and $T$. japonicas stock of 1982 $(t=3.12, p<0.05)$. The estimated $Z / K$ for all assessment sequences ranged from 3.36 to 11.19 using ELEFAN method while ranged from 2.3 to 12.0 using $\mathrm{LBB}$ method. There 
TABLE 2 | Comparison of estimated parameters between ELEFAN method and LBB method with prior information.

\begin{tabular}{|c|c|c|c|c|c|c|c|c|}
\hline \multirow[t]{2}{*}{ Species } & \multirow[t]{2}{*}{ Sequence } & \multirow{2}{*}{$\begin{array}{c}\text { Sampling } \\
\text { years }\end{array}$} & \multicolumn{3}{|c|}{ ELEFAN method } & \multicolumn{3}{|c|}{ LBB method } \\
\hline & & & $L_{\text {inf }}(\mathrm{cm})$ & $Z / K$ & $E$ & $L_{\text {inf }}(\mathrm{cm})$ & $Z / K$ & $E$ \\
\hline \multirow[t]{7}{*}{ Decapterus maruadsi } & 1 & 1992 & 29.7 & 4.26 & 0.70 & 30.3 (29.8-30.8) & $4.4(4.1-4.7)$ & 0.76 \\
\hline & 2 & 1998 & 32.0 & 4.35 & 0.72 & $31.7(31.1-32.2)$ & $4.5(4.1-5.2)$ & 0.79 \\
\hline & 3 & 2006 & 30.5 & 5.48 & 0.76 & $27.5(27.0-28.0)$ & $2.7(2.5-2.9)$ & 0.64 \\
\hline & 4 & 2007 & 32.9 & 3.57 & 0.73 & $32.9(32.3-33.4)$ & $3.6(3.3-3.7)$ & 0.78 \\
\hline & 5 & 2009 & 26.8 & 5.33 & 0.78 & $27.7(27.2-28.1)$ & $4.9(4.4-5.3)$ & 0.80 \\
\hline & 6 & 2010 & 25.5 & 4.09 & 0.71 & $26.3(25.8-26.6)$ & $12(11-13)$ & 0.86 \\
\hline & 7 & 2012 & 23.9 & 3.36 & 0.63 & $24.2(23.9-24.5)$ & $3.2(2.9-3.5)$ & 0.73 \\
\hline \multirow[t]{4}{*}{ Evynnis cardinalis } & 8 & 1962 & 27.6 & 4.89 & 0.49 & $27.9(27.4-28.4)$ & $5(4.6-5.2)$ & 0.58 \\
\hline & 9 & 1999 & 25.9 & 6.92 & 0.62 & $22.0(22.4-23.1)$ & $5.6(5.4-5.8)$ & 0.58 \\
\hline & 10 & 2006 & 23.0 & 5.94 & 0.60 & $22.7(22.3-23.2)$ & $6.3(5.9-6.7)$ & 0.69 \\
\hline & 11 & 2015 & 23.5 & 5.79 & 0.58 & 23.4 (23.1-23.9) & $6.8(6.5-7.3)$ & 0.70 \\
\hline \multirow[t]{3}{*}{ Nemipterus bathybius } & 12 & 1992 & 24.2 & 5.67 & 0.57 & $24.4(24.1-24.8)$ & $3.1(2.9-3.3)$ & 0.51 \\
\hline & 13 & 1997 & 22.0 & 6.29 & 0.62 & $22.1(22.0-22.3)$ & $2.6(2.5-2.7)$ & 0.61 \\
\hline & 14 & 2009 & 23.6 & 5.54 & 0.58 & $24.1(23.8-24.5)$ & $4.9(4.6-5.1)$ & 0.62 \\
\hline \multirow[t]{8}{*}{ Nemipterus virgatus } & 15 & 1960 & 32.6 & 4.08 & 0.34 & 32.1 (31.5-32.6) & $2.3(2.1-2.4)$ & 0.26 \\
\hline & 16 & 1962 & 33.5 & 4.37 & 0.47 & $33.1(32.4-33.6)$ & $4.3(4-4.8)$ & 0.58 \\
\hline & 17 & 1992 & 34.1 & 6.85 & 0.62 & $34.6(34.1-35.2)$ & $9.3(8.4-10)$ & 0.73 \\
\hline & 18 & 1998 & 32.9 & 6.89 & 0.61 & $33.6(33.1-34.4)$ & $4.1(3.9-4.4)$ & 0.56 \\
\hline & 19 & 2006 & 32.1 & 6.63 & 0.60 & $32.8(32.3-33.4)$ & $6(5.7-6.3)$ & 0.62 \\
\hline & 20 & 2007 & 31.5 & 8.45 & 0.71 & $31.5(30.9-32.1)$ & $11(10-12)$ & 0.77 \\
\hline & 21 & 2009 & 31.2 & 9.40 & 0.74 & $31.4(30.8-32)$ & $8.9(8.3-9.4)$ & 0.75 \\
\hline & 22 & 2012 & 32.0 & 7.07 & 0.56 & $32.5(32.0-33.0)$ & $12(11-13)$ & 0.77 \\
\hline \multirow[t]{2}{*}{ Priacanthus macracanthus } & 23 & 1999 & 29.3 & 5.06 & 0.68 & 28.5 (28.2-29.2) & $2.8(2.6-3.1)$ & 0.58 \\
\hline & 24 & 2015 & 29.1 & 6.53 & 0.70 & $29(28.4-29.4)$ & $3.5(3.3-3.8)$ & 0.59 \\
\hline Priacanthus tayenus & 25 & 1999 & 29.4 & 5.72 & 0.68 & $29.4(29.3-29.7)$ & $5.8(5.5-6.1)$ & 0.67 \\
\hline Saurida undosquamis & 26 & 1999 & 45.5 & 5.07 & 0.56 & 45.5 (44.4-46.3) & $8.7(8.2-9.5)$ & 0.77 \\
\hline Trachurus japonicus & 27 & 1999 & 31.2 & 5.12 & 0.58 & $31.6(31.1-32.0)$ & $5.3(4.9-5.5)$ & 0.67 \\
\hline \multirow[t]{3}{*}{ Trichiurus japonicus } & 28 & 1982 & 62.2 & 4.57 & 0.71 & $58.2(57.2-59.3)$ & $3.7(3.4-4.3)$ & 0.80 \\
\hline & 29 & 1999 & 70.0 & 11.19 & 0.87 & $70.3(68.5-71.6)$ & $7.8(7.5-8.2)$ & 0.84 \\
\hline & 30 & 2015 & 58.5 & 5.86 & 0.59 & $58.3(57.3-59.1)$ & $5.3(5-5.5)$ & 0.63 \\
\hline
\end{tabular}

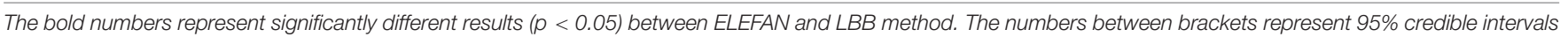
for the parameters.

were not significant differences in estimated $Z / K$ between ELEFAN method and LBB method in 11 assessment sequences (No. 1, 2, 4, 5, 7, 8, 10, 16, 21, 25, and 27, Table 2).

The estimated exploitation rates for all assessment sequences ranged from 0.34 to 0.87 using ELEFAN method while ranged from 0.26 to 0.86 using $\mathrm{LBB}$ method. The lowest value of exploitation rate occurred in $N$. virgatus stock of 1960 using both the two method. The highest value of exploitation rate occurred in T. japonicus stock of 1999, and D. maruadsi stock of 2010 for ELEFAN method and LBB method, respectively. There were significant differences in estimated $E$ between ELEFAN method and LBB method in 16 assessment sequences (Table 2). Estimated exploitation rates for three assessment sequences, E. cardinalis stock of 1962 and $N$. virgatus stock of 1960 and 1962 were below 0.5 using LBB method, and only N. virgatus stock of 1960 were below 0.5 using LBB method (Table 2). Therefore, most of the fish stocks faced with overfishing during the assessment years.

\section{LBB Method With and Without Prior Information}

There were significant differences in 20 assessment sequences $(p<0.05)$ in estimated $L_{\text {inf }}$ using LBB method with and without prior information, and 10 assessment sequences (No. $5,7,12,18,20,23,24,25,26$, and 28) were insensitive to the prior information (Table 3 ). As for estimated $B / B_{M S Y}$, there were not significant differences using LBB method with and without prior information in only 2 assessment sequences (No. 6 and 17). In terms of exploitation statuses $\left(B / B_{M S Y}\right), 9$ assessment sequences (No. 3, 4, 8, 13, 14, 16, 18, 23, and 24) showed different exploitation status using LBB method with and without prior information. For example, D. maruadsi stock of 2006 and 2007 were in overexploited status using LBB with 
TABLE 3 | Comparison of assessment results of LBB method with and without prior information.

\begin{tabular}{|c|c|c|c|c|c|c|c|c|}
\hline \multirow[t]{2}{*}{ Species } & \multirow[t]{2}{*}{ Sequence } & \multirow{2}{*}{$\begin{array}{c}\text { Sampling } \\
\text { years }\end{array}$} & \multicolumn{3}{|c|}{ With prior information } & \multicolumn{3}{|c|}{ Without prior information } \\
\hline & & & $L_{\text {inf }}(\mathrm{cm})$ & $L_{c} / L_{c \_o p t}$ & $B / B_{M S Y}$ & $L_{\text {inf }}(\mathrm{cm})$ & $L_{c} / L_{c_{-} o p t}$ & $B / B_{M S Y}$ \\
\hline \multirow{7}{*}{$\begin{array}{l}\text { Decapterus } \\
\text { maruadsi }\end{array}$} & 1 & 1992 & $30.3(29.8-30.8)$ & 0.65 & $0.33(0.27-0.41)$ & $31.6(31.1-32.2)$ & 0.68 & $0.4(0.28-0.56)$ \\
\hline & 2 & 1998 & $31.7(31.1-32.2)$ & 0.79 & $0.33(0.24-0.45)$ & $30.7(30.3-31.1)$ & 0.84 & $0.47(0.31-0.74)$ \\
\hline & 3 & 2006 & $27.5(27.0-28.0)$ & 0.75 & $0.88(0.63-1.2)$ & $26.1(25.8-26.6)$ & 0.93 & $1.7(0.36-3)$ \\
\hline & 4 & 2007 & $32.9(32.3-33.4)$ & 0.46 & $0.24(0.18-0.3)$ & 29.9 (29.3-30.6) & 0.64 & $0.98(0.48-1.7)$ \\
\hline & 5 & 2009 & $27.7(27.2-28.1)$ & 0.75 & $0.31(0.23-0.41)$ & $27.5(27.1-27.9)$ & 0.87 & $0.58(0.38-0.84)$ \\
\hline & 6 & 2010 & $26.3(25.8-26.6)$ & 0.85 & $0.13(0.098-0.16)$ & $29.6(29.3-30.2)$ & 0.84 & $0.13(0.091-0.16)$ \\
\hline & 7 & 2012 & $24.2(23.9-24.5)$ & 0.95 & $0.58(0.43-0.77)$ & 23.9 (23.6-24.3) & 0.86 & $0.38(0.22-0.56)$ \\
\hline \multirow{4}{*}{$\begin{array}{l}\text { Evynnis } \\
\text { cardinalis }\end{array}$} & 8 & 1962 & $27.9(27.4-28.4)$ & 0.74 & $0.86(0.62-1)$ & 25.4 (25-25.8) & 0.63 & $0.54(0.33-0.86)$ \\
\hline & 9 & 1999 & $22.0(22.4-23.1)$ & 0.54 & $2.5(1-4.4)$ & $21.0(20.8-21.3)$ & 0.38 & $1.6(0.51-2.7)$ \\
\hline & 10 & 2006 & $22.7(22.3-23.2)$ & 0.82 & $0.56(0.44-0.65)$ & $23.7(23.4-24.1)$ & 0.6 & $0.16(0.11-0.23)$ \\
\hline & 11 & 2015 & $23.4(23.1-23.9)$ & 0.78 & $0.53(0.45-0.64)$ & $21.2(20.8-21.4)$ & 0.7 & $0.36(0.25-0.48)$ \\
\hline \multirow{3}{*}{$\begin{array}{l}\text { Nemipterus } \\
\text { bathybius }\end{array}$} & 12 & 1992 & $24.4(24.1-24.8)$ & 1.2 & $2.1(0.82-3.7)$ & 23.9 (23.6-24.3) & 0.94 & $1.3(0.81-2)$ \\
\hline & 13 & 1997 & $22.1(22.0-22.3)$ & 1.5 & $3(0.55-8.8)$ & $25.0(24.7-25.5)$ & 0.83 & $0.52(0.35-72)$ \\
\hline & 14 & 2009 & $24.1(23.8-24.5)$ & 0.9 & $0.89(0.68-1.1)$ & $27.6(27.1-28.2)$ & 0.61 & $0.2(0.14-0.3)$ \\
\hline \multirow{8}{*}{$\begin{array}{l}\text { Nemipterus } \\
\text { virgatus }\end{array}$} & 15 & 1960 & $32.1(31.5-32.6)$ & 1.0 & $2.7(1.1-5.5)$ & 27.7 (27.5-28) & 0.74 & $2(0.68-6.3)$ \\
\hline & 16 & 1962 & $33.1(32.4-33.6)$ & 0.86 & $0.96(0.74-1.2)$ & $30.7(30.1-31.2)$ & 0.7 & $0.5(0.26-0.76)$ \\
\hline & 17 & 1992 & $34.6(34.1-35.2)$ & 1.1 & $0.59(0.46-0.73)$ & $31.7(31.2-32.2)$ & 1.1 & $0.54(0.39-0.7)$ \\
\hline & 18 & 1998 & $33.6(33.1-34.4)$ & 0.92 & $1.5(1.1-2.2)$ & $32.8(32.2-33.4)$ & 0.69 & $0.68(0.46-1)$ \\
\hline & 19 & 2006 & $32.8(32.3-33.4)$ & 0.76 & $0.7(0.59-0.83)$ & $29.9(29.3-30.3)$ & 0.65 & $0.42(0.27-0.6)$ \\
\hline & 20 & 2007 & $31.5(30.9-32.1)$ & 0.81 & $0.27(0.23-0.31)$ & 31.1 (30.6-31.6) & 0.64 & $0.1(0.069-0.14)$ \\
\hline & 21 & 2009 & $31.4(30.8-32.0)$ & 0.73 & $0.33(0.27-0.39)$ & $38.1(37.4-38.8)$ & 0.46 & $0.052(0.035-0.077)$ \\
\hline & 22 & 2012 & $32.5(32.0-33.0)$ & 0.89 & $0.4(0.33-0.47)$ & 26.5 (25.9-26.9) & 0.78 & $0.29(0.2-0.39)$ \\
\hline \multirow{3}{*}{$\begin{array}{l}\text { Priacanthus } \\
\text { macracanthus }\end{array}$} & 23 & 1999 & $28.5(28.2-29.2)$ & 0.73 & $1.1(0.8-1.7)$ & $27.8(27.3-28.2)$ & 0.77 & 1.4 (0.67-2.3) \\
\hline & & & & & & & & \\
\hline & 24 & 2015 & 29 (28.4-29.4) & 0.66 & $0.96(0.64-1.2)$ & $29.8(29.3-30.4)$ & 0.55 & $0.47(0.31-0.64)$ \\
\hline $\begin{array}{l}\text { Priacanthus } \\
\text { tayenus }\end{array}$ & 25 & 1999 & $29.4(29.3-29.7)$ & 0.62 & $2.3(0.72-4.1)$ & $29.3(29.2-29.5)$ & 0.56 & $1.9(0.47-3.6)$ \\
\hline $\begin{array}{l}\text { Saurida } \\
\text { undosquamis }\end{array}$ & 26 & 1999 & 45.5 (44.4-46.3) & 0.55 & $0.21(0.17-0.24)$ & 44.2 (43.6-44.9) & 0.46 & $0.085(0.57-0.12)$ \\
\hline $\begin{array}{l}\text { Trachurus } \\
\text { japonicus }\end{array}$ & 27 & 1999 & $31.6(31.1-32.0)$ & 0.94 & $0.72(0.57-0.87)$ & 34.8 (34.2-35.3) & 0.69 & $0.22(0.15-0.32)$ \\
\hline \multirow{3}{*}{$\begin{array}{l}\text { Trichiurus } \\
\text { japonicus }\end{array}$} & 28 & 1982 & $58.2(57.2-59.3)$ & 0.87 & $0.42(0.29-0.59)$ & $58.1(57.4-59.1)$ & 0.67 & $0.096(0.03-0.24)$ \\
\hline & 29 & 1999 & $70.3(68.5-71.6)$ & 0.3 & $0.067(0.057-0.082)$ & $67.0(65.8-68.3)$ & 0.33 & $0.1(0.079-0.13)$ \\
\hline & 30 & 2015 & $58.3(57.3-59.1)$ & 0.5 & $0.54(0.45-0.66)$ & $63.1(62.1-64)$ & 0.35 & $0.12(0.085-0.17)$ \\
\hline
\end{tabular}

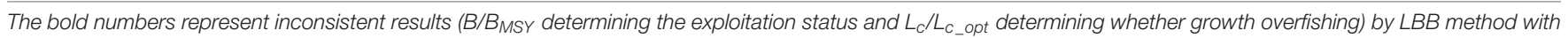
and without prior information. The numbers between brackets represent $95 \%$ credible intervals for the parameters.

prior information, but in fully exploited and underdeveloped status without prior information. Four assessment sequences (No. 12, 13, 15, and 17) showed growth overfishing were not happening using LBB method with prior information, and only 1 assessment sequence (No. 17) showed the same results without prior information (Table 3).

\section{Model Performance of Three Types of LBB Methods}

Reference point outputs (Table 4) showed that the three types of LBB methods (original LBB, LBB-1, and LBB-2) produced the same results when detecting the occurrence of growth overfishing, i.e., $86.7 \%$ of the 30 target stocks were facing growth overfishing $\left(L_{c} / L_{C_{-} o p t}<1\right)$, except for 4 assessment sequences (No. 12, 13, 15, and 17). The original LBB and LBB-2 models produced the same decisions if the stocks had been overfished $\left(B / B_{M S Y}\right)$. LBB-1 model produced similar results with the other two models, except for 5 assessment sequences (No. 3, 8, 18, 23 , and 24). The underestimation of estimated $B / B_{M S Y}$ for the 5 assessment sequences made their exploitation status negatively, i.e., the original LBB and LBB- 2 models indicated 4 stocks (No. $3,8,23$, and 24) were fully exploited while LBB-1 showed they 
TABLE 4 | Comparison of assessment results of LBB method and two modified methods.

\begin{tabular}{|c|c|c|c|c|c|c|c|c|}
\hline \multirow[t]{2}{*}{ Species } & \multirow[t]{2}{*}{ Sequence } & \multirow{2}{*}{$\begin{array}{c}\text { Sampling } \\
\text { years }\end{array}$} & \multicolumn{3}{|c|}{$L_{c} / L_{c_{-} o p t}$} & \multicolumn{3}{|c|}{$B / B_{M S Y}$} \\
\hline & & & LBB & LBB-1 & LBB-2 & LBB & LBB-1 & LBB-2 \\
\hline \multirow[t]{7}{*}{ Decapterus maruadsi } & 1 & 1992 & 0.65 & 0.63 & 0.64 & $0.33(0.27-0.41)$ & $0.23(0.18-0.28)$ & $0.27(0.22-0.34)$ \\
\hline & 2 & 1998 & 0.79 & 0.75 & 0.77 & $0.33(0.24-0.45)$ & $0.23(0.18-0.27)$ & $0.27(0.18-0.38)$ \\
\hline & 3 & 2006 & 0.75 & 0.71 & 0.74 & $0.88(0.63-1.2)$ & $0.5(0.38-0.61)$ & $0.82(0.55-1.1)$ \\
\hline & 4 & 2007 & 0.46 & 0.44 & 0.45 & $0.24(0.18-0.3)$ & $0.15(0.11-0.18)$ & $0.21(0.16-0.29)$ \\
\hline & 5 & 2009 & 0.75 & 0.72 & 0.74 & $0.31(0.23-0.41)$ & $0.22(0.18-0.27)$ & $0.28(0.21-0.35)$ \\
\hline & 6 & 2010 & 0.85 & 0.83 & 0.85 & $0.13(0.098-0.16)$ & $0.11(0.083-0.14)$ & $0.12(0.093-0.15)$ \\
\hline & 7 & 2012 & 0.95 & 0.92 & 0.92 & $0.58(0.43-0.77)$ & $0.4(0.32-0.5)$ & $0.41(0.31-0.53)$ \\
\hline \multirow[t]{4}{*}{ Evynnis cardinalis } & 8 & 1962 & 0.74 & 0.7 & 0.75 & $0.86(0.62-1)$ & $0.58(0.48-0.7)$ & $0.86(0.66-1.1)$ \\
\hline & 9 & 1999 & 0.54 & 0.63 & 0.54 & $2.5(1-4.4)$ & $2.5(0.85-4.5)$ & $2.5(1.1-4.6)$ \\
\hline & 10 & 2006 & 0.82 & 0.79 & 0.8 & $0.56(0.44-0.65)$ & $0.42(0.36-0.49)$ & $0.45(0.38-0.55)$ \\
\hline & 11 & 2015 & 0.78 & 0.75 & 0.77 & $0.53(0.45-0.64)$ & $0.39(0.34-0.44)$ & $0.48(0.39-0.59)$ \\
\hline \multirow[t]{3}{*}{ Nemipterus bathybius } & 12 & 1992 & 1.2 & 1.0 & 1.1 & $2.1(0.82-3.7)$ & $1.3(0.95-1.5)$ & $2.1(0.71-3.8)$ \\
\hline & 13 & 1997 & 1.5 & 1.2 & 1.3 & $3(0.55-8.8)$ & $1.4(1-1.9)$ & $2(0.48-3.2)$ \\
\hline & 14 & 2009 & 0.9 & 0.87 & 0.89 & $0.89(0.68-1.1)$ & $0.83(0.75-0.94)$ & $0.84(0.72-0.91)$ \\
\hline \multirow[t]{8}{*}{ Nemipterus virgatus } & 15 & 1960 & 1.0 & 1.0 & 1.0 & $2.7(1.1-5.5)$ & $2.6(0.79-5.7)$ & $2.6(0.67-5.6)$ \\
\hline & 16 & 1962 & 0.86 & 0.82 & 0.82 & $0.96(0.74-1.2)$ & $0.87(0.75-0.91)$ & $0.85(0.83-0.91)$ \\
\hline & 17 & 1992 & 1.1 & 1.1 & 1.1 & $0.59(0.46-0.73)$ & $0.48(0.41-0.58)$ & $0.58(0.47-0.7)$ \\
\hline & 18 & 1998 & 0.92 & 0.85 & 0.91 & $1.5(1.1-2.2)$ & $0.99(0.81-1.2)$ & $1.5(0.86-2)$ \\
\hline & 19 & 2006 & 0.76 & 0.74 & 0.76 & 0.7 (0.59-0.83) & $0.54(0.46-0.62)$ & $0.7(0.57-0.85)$ \\
\hline & 20 & 2007 & 0.81 & 0.79 & 0.8 & $0.27(0.23-0.31)$ & $0.22(0.19-0.25)$ & $0.24(0.2-0.29)$ \\
\hline & 21 & 2009 & 0.73 & 0.72 & 0.72 & $0.33(0.27-0.39)$ & $0.28(0.24-0.32)$ & $0.31(0.26-0.35)$ \\
\hline & 22 & 2012 & 0.89 & 0.86 & 0.89 & $0.4(0.33-0.47)$ & $0.32(0.28-0.36)$ & $0.39(0.34-0.46)$ \\
\hline \multirow[t]{2}{*}{ Priacanthus macracanthus } & 23 & 1999 & 0.73 & 0.67 & 0.72 & $1.1(0.8-1.7)$ & $0.59(0.46-0.73)$ & $1.1(0.7-1.6)$ \\
\hline & 24 & 2015 & 0.66 & 0.62 & 0.67 & $0.96(0.64-1.2)$ & $0.57(0.42-0.71)$ & $0.93(0.71-1.3)$ \\
\hline Priacanthus tayenus & 25 & 1999 & 0.62 & 0.76 & 0.63 & $2.3(0.72-4.1)$ & $2.5(0.7-5)$ & $2.3(0.68-7.5)$ \\
\hline Saurida undosquamis & 26 & 1999 & 0.55 & 0.54 & 0.54 & $0.21(0.17-0.24)$ & $0.17(0.15-0.2)$ & $0.17(0.15-0.2)$ \\
\hline Trachurus japonicus & 27 & 1999 & 0.94 & 0.91 & 0.93 & $0.72(0.57-0.87)$ & $0.55(0.47-0.67)$ & $0.62(0.47-0.76)$ \\
\hline \multirow[t]{3}{*}{ Trichiurus japonicus } & 28 & 1982 & 0.87 & 0.84 & 0.85 & $0.42(0.29-0.59)$ & $0.3(0.22-0.39)$ & $0.3(0.23-0.37)$ \\
\hline & 29 & 1999 & 0.30 & 0.30 & 0.30 & $0.067(0.057-0.082)$ & $0.052(0.044-0.061)$ & $0.067(0.055-0.08)$ \\
\hline & 30 & 2015 & 0.50 & 0.49 & 0.49 & $0.54(0.45-0.66)$ & $0.38(0.31-0.46)$ & $0.46(0.33-0.61)$ \\
\hline
\end{tabular}

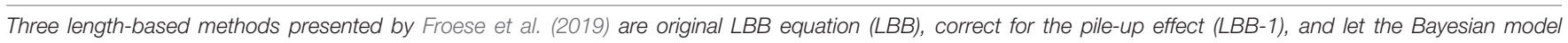

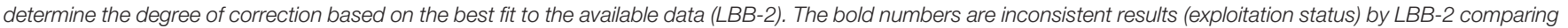
with other two models. The numbers between brackets represent 95\% credible intervals for the parameters.

were overexploited; the original LBB and LBB-2 models showed $N$. virgatus stock of 1998 (No. 18) were underdeveloped while LBB-1 indicated it was fully exploited. The estimated $B / B_{M S Y}$ showed $83.4 \%$ of the 30 target stocks were in overexploited status or fully exploited status while E. cardinalis stock of 1999, N. bathybius of 1992 and 1997, N. virgatus of 1960, and P. tayenus of 1999 were in underdeveloped status (Table 4). In summary, the original LBB and LBB-2 models produced similar results, indicating Bayesian model can help determine the degree of correction.

\section{DISCUSSION}

This study is the first attempt to apply both the traditional ELEFAN method and the newly developed LBB method across the main exploited fish stocks in the Beibu Gulf, and test the effect of prior information on LBB method. The results showed that the two length-based methods presented different ability in estimating exploitation rates, and the prior information from ELEFAN method was effective for LBB method. The estimated $L_{c} / L_{c_{-} o p t}$ and $B / B_{M S Y}$ of LBB method suggest a pressing situation for the fisheries in Beibu Gulf, as $86.7 \%$ of the 30 target stocks had been suffering from growth overfishing, and $83.3 \%$ had been overexploited or fully exploited.

\section{Model Performance}

There have been burgeoning literatures on the use of relatively simple methods to evaluate data-poor fisheries status. These approaches range from using life history characteristics as a guide to the vulnerability of fishing (Goodwin et al., 2006; Punt et al., 2011; McCully Phillips et al., 2015), to more holistic evaluations for obtaining management reference points and harvest control rules (Cope and Punt, 2009), or extensive assessment-based meta-analysis (Armelloni et al., 2021) using 


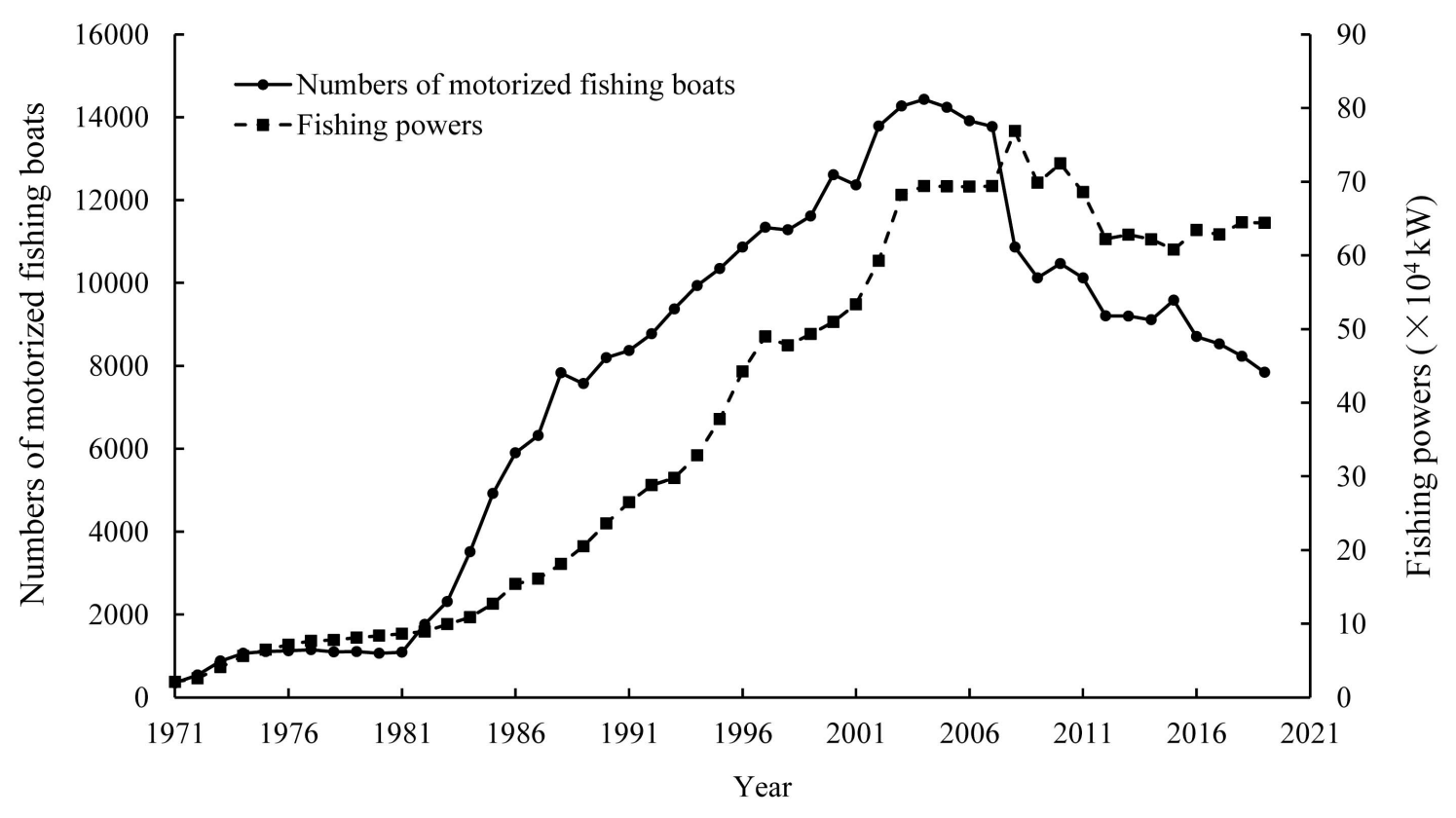

FIGURE 2 | Numbers of motorized fishing boats and total fishing powers of Guangxi Province.

catch data, and auxiliary information (e.g., age-length data, life history parameters). Among the various data, fish growth in body length is discrepant by species and convenient to access.

Fish growth in body length of ELEFAN and LBB method both are assumed to follow von Bertalanffy equation (Pauly and David, 1981; Froese et al., 2018). However, the parameters in the two methods are estimated in different ways: the growth and mortality parameters (i.e., $M, F$, and $K$ ) in ELEFAN method can be directly calculated from empirical formulas or procedures while the ratios $M / K$ and $F / M$ are estimated, instead of the absolute values of $F, M$, and $K$ in the LBB method. Compared with LBB method, ELEFAN method can provide the estimated growth and mortality parameters which are essential in full stock assessment or ecosystem based assessment, but relatively limited management reference points. Gulland (1983) recommend that 0.5 may be the suitable exploitation rate for fish stocks in temperate water. However, fish stocks in tropical and subtropical areas (e.g., the Beibu Gulf) have short lifecycles and rapid growth, and they can sustain high exploitation rates (Wang et al., 2012). Therefore, the exploitation rate may be insufficient for the fishery management in Beibu Gulf while $L_{c} / L_{c_{-} \text {opt }}$ and $B / B_{M S Y}$ provided by LBB method are commonly used management reference points (Zhang et al., 2021b). Our study showed the prior information from ELEFAN method was effective for LBB method (Supplementary Figure 1) because most of the assessment sequences produced significantly different results with and without prior information.

The parameters of LBB method are calculated by a Bayesian Monte Carlo Markov Chain (MCMC) approach (Cowles and Carlin, 1996), which has been widely used in fishery data analysis (Haddon, 2010). With this Bayesian framework, it is straightforward to calculate credible intervals for multiple parameters. In this study, $95 \%$ credible intervals of $B / B_{M S Y}$ and $L_{c} / L_{c_{-} o p t}$ were calculated, and these results can provide alternative information sources which can support decisionmaking. Besides, we also applied two modified LBB models (LBB-1 and LBB-2) with corrections for the pile-up effect (Froese et al., 2019; Hordyk et al., 2019). The results (Table 4) showed estimations of the original LBB method have been little affected by the pile-up effect for most of the assessment sequences.

In addition, we suggest using both ELEFAN and LBB methods to fit length-frequency data of data-poor fish stocks because they are complementary in estimating management reference points.

\section{Challenges in Fisheries Management for the Beibu Gulf}

The Beibu Gulf has multiple ecosystems with estuaries, mangroves, coral reefs, and shelves, which provide comfortable habitats for spawning, feeding, and nursery areas for abundant fish species (Qiu et al., 2008). As reported to date, 960 fish species inhabit this embayment, which belonging to 162 fish families. The main fishing gears are trawl, purse seine, gill net, hook and set nets, and the trawl fishery accounts for more than $70 \%$ of the total catch (Zou et al., 2013). There are not available statistical catch data in the Beibu Gulf because catch data are gathered by administrative districts (e.g., provinces in China), instead of sea areas. Therefore, it was considered to be a data-poor fishing ground, and the length-based methods used in this study may fill a gap in knowledge of biomass levels and exploitation status of main fish stocks in the Beibu Gulf. 
Zou et al. (2013) has estimated the fishery catch of the Beibu Gulf to be $85.7 \times 10^{4} \mathrm{t}$ in 2012 , including $65.7 \times 10^{4} \mathrm{t}$ caught by China, and $20.0 \times 10^{4} \mathrm{t}$ caught by Vietnam. The numbers of motorized fishing boats and total fishing powers of Guangxi Province were selected to represent the long-term trend of fishing efforts in the Beibu Gulf (Figure 2). Before China's reform and opening up in 1978, the number of motorized fishing boats in Guangxi Province was less than 1200, and total fishing powers was no more than $8.5 \times 10^{4} \mathrm{~kW}$. In $1980 \mathrm{~s}$ and $1990 \mathrm{~s}$, the fishing efforts had been rapidly increasing and some indications of overfishing have appeared, e.g., catch rates trend downward (Qiu et al., 2008), catch composition has changed significantly (Chen et al., 2011), and miniaturization, early sexual maturity and accelerated growth have occurred in main commercial fish species (Zhang et al., 2020a). The indications of overfishing were consistent with our assessment results, which showed the assessed fish stocks had been overexploited in the 1990s.

In the recent two decades, a series of conservative management measures have been implemented by Chinese government in the SCS, including "double control" system, summer fishing moratorium, "zero-growth" and "negativegrowth" strategies (Shen and Heino, 2014; Cao et al., 2017). Benefiting from the management measures, the fishing efforts had been stabilized and then decreased (Figure 2). Recent studies have shown that the management measures to reduce fishing pressure had been playing an important role for fishery resources recovery, e.g., the average daily yields of fishing boats and output values have increased after the summer fishing moratorium (Su et al., 2019), and these measures have a positive influence on the biological characteristics of this commercial fish species (Zhang et al., 2021a). However, our results showed the main commercial fish stocks were still in overexploited status in recent years (Table 4). Beibu Gulf is a co-developed area of fishery resources by both China and Vietnam, but until now, only China makes policy efforts to reduce fishing pressure. For example, during the 3.5-months summer fishing moratorium, all fishing gears (except for rod fishing) of China stopped fishing in the Beibu Gulf, but the fishing boats of Vietnam were still active in this sea area. Therefore, we emphasize collaboration mechanism should be established by the two countries for management and sustainability of fishery resources in the Beibu Gulf.

\section{REFERENCES}

Amorim, P., Sousa, P., Jardim, E., and Menezes, G. M. (2019). Sustainability status of data-limited fisheries: global challenges for snapper and grouper. Front. Mar. Sci. 6:654. doi: 10.3389/fmars.2019.00654

Armelloni, E. N., Scanu, M., Masnadi, F., Coro, G., Angelini, N., and Scarcella, G. (2021). Data poor approach for the assessment of the main target species of rapido trawl fishery in Adriatic Sea. Front. Mar. Sci. 8:552076. doi: 10.3389/ fmars.2021.552076

Baldé, B. S., Fall, M., Kantoussan, J., Sow, F. N., Diouf, M., and Brehmer, P. (2019). Fish-length based indicators for improved management of the sardinella fisheries in Senegal. Reg. Stud. Mar. Sci. 31:100801. doi: 10.1016/j.rsma.2019. 100801

\section{DATA AVAILABILITY STATEMENT}

The raw data supporting the conclusions of this article will be made available by the authors, without undue reservation.

\section{ETHICS STATEMENT}

The animal study was reviewed and approved by South China Sea Fisheries Research Institute Animal Welfare Committee.

\section{AUTHOR CONTRIBUTIONS}

KZ conceived the study and wrote the first draft. JL, GH, and DS performed the data analyses and prepared the graphs. $\mathrm{ZH}$, $\mathrm{ZC}$, and YQ provided the original length data and revised the manuscript. All the authors contributed to the article and approved the submitted version.

\section{FUNDING}

This work was supported by the Key Research and Development Project of Guangdong Province (2020B1111030001), the National Natural Science Foundation of China (31602157), and the Central Public-Interest Scientific Institution Basal Research Fund (2020TD05 and 2021SD01).

\section{ACKNOWLEDGMENTS}

The authors are grateful to our colleagues, Youwei Xu, Mingshuai Sun, Xin Liang, and Yuezhong Wang, who have been working at the forefront of marine fishery resources surveys, and crew of R/V Beiyu60011 for sample collection and measurement.

\section{SUPPLEMENTARY MATERIAL}

The Supplementary Material for this article can be found online at: https://www.frontiersin.org/articles/10.3389/fmars. 2021.718052/full\#supplementary-material

Cadrin, S. X., and Dickey-Collas, M. (2015). Stock assessment methods for sustainable fisheries. ICES J. Mar. Sci. 72, 1-6. doi: 10. 1093/icesjms/fsu228

Cao, L., Chen, Y., Dong, S., Hanson, A., Huang, B., Leadbitter, D., et al. (2017). Opportunity for marine fisheries reform in China. Proc. Natl. Acad. Sci. U.S.A. 114, 435-442.

Chen, Z., Qiu, Y., and Xu, S. (2011). Changes in trophic flows and ecosystem properties of the Beibu Gulf ecosystem before and after the collapse of fish stocks. Ocean Coast. Manage. 54, 601-611. doi: 10.1016/j.ocecoaman.2011.06. 003

Cope, J. M., and Punt, A. E. (2009). Length-based reference points for datalimited situations: applications and restrictions. Mar. Coast. Fish. 1, 169-186. doi: $10.1577 / \mathrm{c} 08-025.1$ 
Costello, C., Ovando, D., Hilborn, R., Gaines, S. D., Deschenes, O., and Lester, S. E. (2012). Status and solutions for the world's unassessed fisheries. Science 338, 517-520. doi: 10.1126/science. 1223389

Cowles, M. K., and Carlin, B. P. (1996). Markov chain Monte Carlo convergence diagnostics: a comparative review. J. Am. Stat. Assoc. 91, 883-904. doi: 10.1080/ 01621459.1996 .10476956

Dick, E. J., and Maccall, A. D. (2011). Depletion-Based Stock Reduction Analysis: a catch-based method for determining sustainable yields for data-poor fish stocks. Fish. Res. 110, 331-341. doi: 10.1016/j.fishres.2011.05.007

Food and Agriculture Organization (FAO) (2016). The State of World Fisheries and Aquaculture (SOFIA) Report 2016. Rome: FAO.

Froese, R., Winker, H., Coro, G., Demirel, N., Tsikliras, A. C., Dimarchopoulou, D., et al. (2018). A new approach for estimating stock status from length frequency data. ICES J. Mar. Sci. 75, 2004-2015. doi: 10.1093/icesjms/fsy078

Froese, R., Winker, H., Coro, G., Demirel, N., Tsikliras, A. C., Dimarchopoulou, D., et al. (2019). On the pile-up effect and priors for $L_{\text {inf }}$ and $M / K$ : response to a comment by Hordyk et al. on "A new approach for estimating stock status from length frequency data”. ICES J. Mar. Sci. 76, 461-465. doi: 10.1093/icesjms/ fsy199

Froese, R., Winker, H., Coro, G., Demirel, N., Tsikliras, A. C., Dimarchopoulou, D., et al. (2020). Estimating stock status from relative abundance and resilience. ICES J. Mar. Sci. 77, 527-538. doi: 10.1093/icesjms/fsz230

Gayanilo, F. C., and Pauly, D. (eds) (1997). "FAO-ICLARM stock assessment tools: reference manual," in FAO Computerized Information Series (Fisheries), eds F. C. Gayanilo and D. Pauly (Rome: FAO), 8.

Goodwin, N. B., Grant, A., Perry, A. L., Dulvy, N. K., and Reynolds, J. D. (2006). Life history correlates of density-dependent recruitment in marine fishes. Can. J. Fish. Aquat. Sci. 63, 494-509. doi: 10.1139/f05-234

Gulland, J. A. (1983). Fish Stock Assessment: A Manual of Basic Methods. New York, NY: Wiley Online Library.

Haddon, M. (2010). Modelling and Quantitative Methods in Fisheries, 2nd Edn. New York, NY: Chapman and Hall.

Hordyk, A. R., Loneragan, N. R., and Prince, J. D. (2015). An evaluation of an iterative harvest strategy for data-poor fisheries using the length-based spawning potential ratio assessment methodology. Fish. Res. 171, 20-32. doi: 10.1016/j.fishres.2014.12.018

Hordyk, A. R., Prince, J. D., Carruthers, T. R., and Walters, C. J. (2019). Comment on "A new approach for estimating stock status from length frequency data" by Froese et al. (2018). ICES J. Mar. Sci. 76, 457-460. doi: 10.1093/icesjms/fsy168

Kleisner, K., Zeller, D., Froese, R., and Pauly, D. (2013). Using global catch data for inferences on the world's marine fisheries. Fish. Fish. 14, 293-311. doi: 10.1111/j.1467-2979.2012.00469.x

Liang, C., Xian, W., Liu, S., and Pauly, D. (2020). Assessments of 14 exploited fish and Invertebrate stocks in Chinese waters using the LBB method. Front. Mar. Sci. 7:314. doi: 10.3389/fmars.2020.00314

Liu, Q., Xu, B., Ye, Z., and Ren, Y. (2012). Growth and mortality of small yellow croaker (Larimichthys polyactis) inhabiting Haizhou bay of China. J. Ocean Univ. China 11, 557-561. doi: 10.1007/s11802-012-2099-z

Martell, S., and Froese, R. (2013). A simple method for estimating MSY from catch and resilience. Fish. Fish. 14, 504-514. doi: 10.1111/j.1467-2979.2012.00485.x

Maunder, M. N., and Punt, A. E. (2013). A review of integrated analysis in fisheries stock assessment. Fish. Res. 142, 61-74. doi: 10.1016/j.fishres.2012.07.025

McCully Phillips, S. R., Scott, F., and Ellis, J. R. (2015). Having confidence in productivity susceptibility analyses: a method for underpinning scientific advice on skate stocks? Fish. Res. 171, 87-100. doi: 10.1016/j.fishres.2015.01.005

Nadon, M. O., Ault, J. S., Williams, I. D., Smith, S. G., and DiNardo, G. T. (2015). Length-based assessment of coral reef fish populations in the main and northwestern Hawaiian Islands. Plos One 10:e0133960. doi: 10.1371/journal. pone.0133960.g003

Pauly, D. (1983). Some Simple Methods for the Assessment of Tropical Fish Stocks. FAO Fisheries Technical Paper No. 234. Rome: FAO.

Pauly, D., and David, N. (1981). ELEFAN I, a BASIC program for the objective extraction of growth parameters from length-frequency data. Meeresforschung 28, 205-211.

Pauly, D., and Zeller, D. (2016). Catch reconstructions reveal that global marine fisheries catches are higher than reported and declining. Nat. Commun. $7: 10244$.
Punt, A. E., Smith, D. C., and Smith, A. D. M. (2011). Among-stock comparisons for improving stock assessments of data-poor stocks: the "Robin Hood" approach. ICES J. Mar. Sci. 68, 972-981. doi: 10. 1093/icesjms/fsr039

Qiu, Y., Zeng, X., Chen, T., Yuan, W., and Wang, Y. (2008). Fishery Resources and Management in South China Sea. Beijing: The Ocean Press.

Quinn, T. J., and Deriso, R. B. (1999). Quantitative Fish Dynamics. New York, NY: Oxford University Press.

Shen, G., and Heino, M. (2014). An overview of marine fisheries management in China. Mar. Policy 44, 265-272. doi: 10.1016/j.marpol.2013.09.012

Su, L., Chen, Z., Zhang, K., Xu, Y., Xu, S., and Wang, K. (2021). Decadal-scale variation in mean trophic level in Beibu Gulf based on bottom-trawl survey data. Mar. Coast. Fish. 13, 174-182. doi: 10.1002/mcf2.10144

Su, Y., Chen, G., Zhou, Y., Ma, S., and Wu, Q. (2019). Assessment of impact of summer fishing moratorium in South China Sea during 2015-2017. South China Fish. Sci. 15, 20-28.

Thorson, J. T., Johnson, K. F., Methot, R. D., and Taylor, I. G. (2017). Modelbased estimates of effective sample size in stock assessment models using the Dirichlet-multinomial distribution. Fish. Res. 192, 84-93. doi: 10.1016/j.fishres. 2016.06.005

von Bertalanffy, L. (1938). A quantitative theory of organic growth (inquiries on growth laws II). Hum. Biol. 10, 181-213.

Wang, X., Qiu, Y., Du, F., Lin, Z., Sun, D., and Huang, S. (2012). Population parameters and dynamic pool models of commercial fishes in the Beibu Gulf, northern South China Sea. Chin. J. Oceanol. Limn. 30, 102-117.

Watson, R., and Pauly, D. (2001). Systematic distortions in world fisheries catch trends. Nature 414, 534-536. doi: 10.1038/35107050

Zhang, K., Cai, Y., Liao, B., Jiang, Y., Sun, M., Su, L., et al. (2020a). Population dynamics of threadfin porgy Evynnis cardinalis, an endangered species on IUCN red list in the Beibu Gulf, South China Sea. J. Fish Biol. 97, 479-489. doi: $10.1111 /$ jfb.14398

Zhang, K., Guo, J., Xu, Y., Jiang, Y., Fan, J., Xu, S., et al. (2020b). Long-term variations in fish community structure under multiple stressors in a semiclosed marine ecosystem in the South China Sea. Sci. Total Environ. 745:140892. doi: 10.1016/j.scitotenv.2020.140892

Zhang, K., Geng, P., Li, J., Xu, Y., Kalhoro, M. A., Sun, M., et al. (2021a). Influences of fisheries management measures on biological characteristics of threadfin bream (Nemipterus virgatus) in the Beibu Gulf, South China Sea. Acta Oceanol. Sin. (in press).

Zhang, K., Zhang, J., Shi, D., and Chen, Z. (2021b). Assessment of coral reef fish stocks from the Nansha Islands, South China Sea, using length-based Bayesian biomass estimation. Front. Mar. Sci. 7:610707. doi: 10.3389/fmars.2020.610707

Zhang, K., Liao, B., Xu, Y., Zhang, J., Sun, M., Qiu, Y., et al. (2017). Assessment for allowable catch of fishery resources in the South China Sea based on the statistical data. Haiyang Xuebao 39, 25-33.

Zhou, Y., Xu, H., Liu, Z., and Xue, L. (2002). A study on variation of stock structure of hairtall, Trichiurus haumela in the East China Sea. J. Zhejiang Ocean Univ. (Nat. Sci.). 21, 314-320.

Zou, J., Lin, P., and Wang, Q. (2013). Evaluation of catch in Beibu Gulf of South China Sea in 2012. South Chin. Fish. Sci. 9, 75-81.

Conflict of Interest: The authors declare that the research was conducted in the absence of any commercial or financial relationships that could be construed as a potential conflict of interest.

Publisher's Note: All claims expressed in this article are solely those of the authors and do not necessarily represent those of their affiliated organizations, or those of the publisher, the editors and the reviewers. Any product that may be evaluated in this article, or claim that may be made by its manufacturer, is not guaranteed or endorsed by the publisher.

Copyright (c) 2021 Zhang, Li, Hou, Huang, Shi, Chen and Qiu. This is an open-access article distributed under the terms of the Creative Commons Attribution License (CC BY). The use, distribution or reproduction in other forums is permitted, provided the original author(s) and the copyright owner(s) are credited and that the original publication in this journal is cited, in accordance with accepted academic practice. No use, distribution or reproduction is permitted which does not comply with these terms. 